\title{
A prestação de contas com a morte: um olhar sobre os testamentos e inventários post-mortem (nordeste paulista, séculos XVIII e XIX)
}

\section{Charges and obligations with death: a study on inventories and wills post- mortem (northeast of São Paulo, 18th and 19th centuries)}

\section{Lelio Luiz de Oliveira}

Universidade de São Paulo

\section{Resumo}

Este artigo é resultado de um estudo sobre os comportamentos e estratégias dos indivíduos frente à morte, relatadas em testamentos e inventários post-mortem, bem como sobre os bens e valores deixados para custear os rituais, funerais e instituições religiosas, com a intenção de preservar a alma. A pesquisa comprova a permanência das atitudes humanas influenciadas pelos ditames religiosos relacionados à morte, $\mathrm{e}$ as tentativas de demonstração de piedade para com as pessoas próximas durante a vida, mesmo diante do processo de laicização da sociedade. Para a análise foram selecionados documentos que representam comportamentos semelhantes entre os moradores do Sertão do Rio Pardo, nordeste paulista, entre os anos de 1786 a 1858 , período de efetiva ocupação populacional e dinamização das atividades econômicas do território voltadas para o abastecimento interno.

Palavras-chave: Preço da morte; Testamentos; Inventários post-mortem.

\section{Abstract}

This article is the result of a study of the behaviors and strategies of individuals facing death reported in wills and postmortem inventories, as well as on the goods and values left to pay for rituals, funerals and religious institutions, with the intention of preserving the soul. The research proves the permanence of human attitudes influenced by religious dictates related to death, and attempts to demonstrate piety towards people close to them during life, even in the process of secularization of society. For the analysis, there were selected documents representing similar behaviors among residents of the Sertão do Rio Pardo, northeast of São Paulo, between the years of 1786 to 1858 , period of effective population occupation and dynamization of the economic activities of the territory, focused on internal supply.

Keywords: Death price; Wills; Post-mortem inventories. 

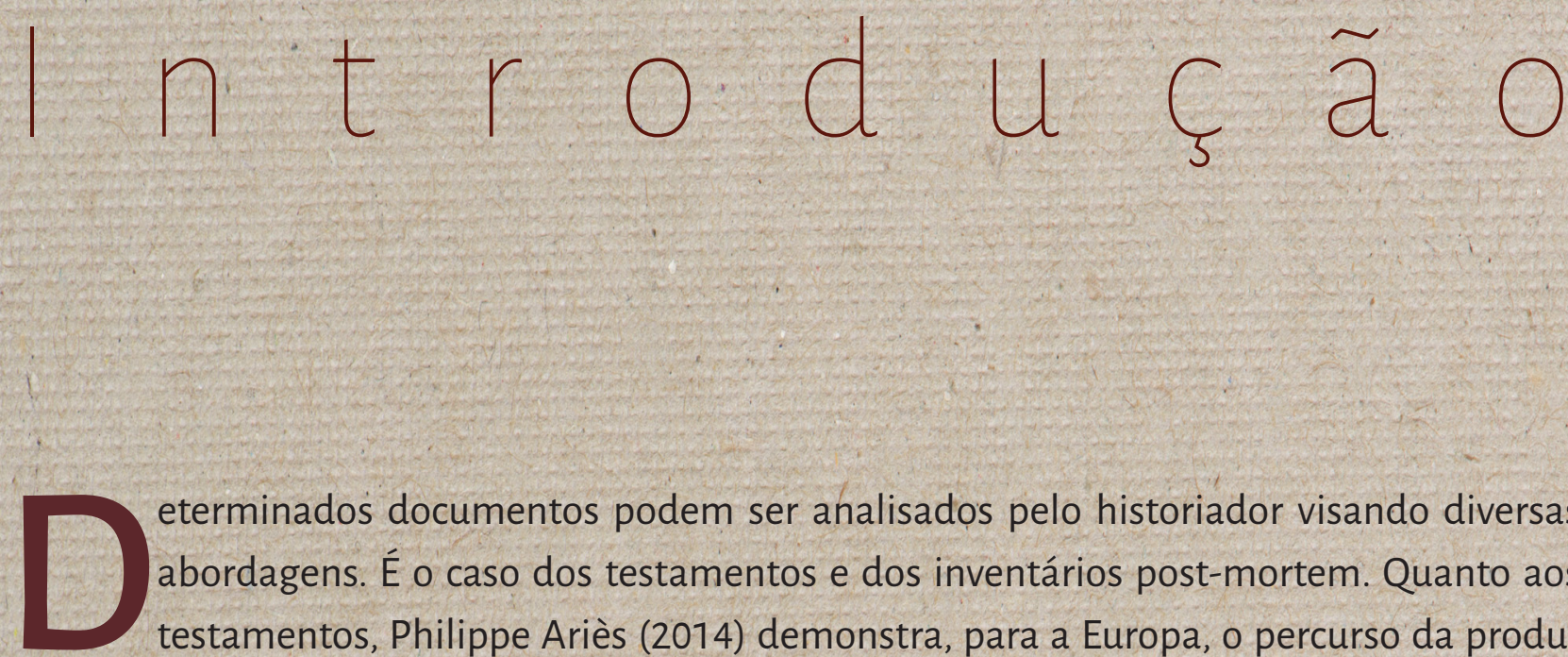

eterminados documentos podem ser analisados pelo historiador visando diversas abordagens. É o caso dos testamentos e dos inventários post-mortem. Quanto aos testamentos, Philippe Ariès (2014) demonstra, para a Europa, o percurso da produção deste documento desde seu ressurgimento com um novo perfil no século XII até o século XVIII, período em que a Igreja impôs aos homens o encargo de testar. Vale ressaltar que, desde meados do século XVIII, o testamento foi ao mesmo tempo perdendo o sentido religioso e ganhando o contorno civil.

Era em primeiro lugar um ato religioso, imposto pela Igreja, mesmo aos mais desprovidos. Considerando um sacramental, como a água benta, a lgreja impôs-lhe o uso, tornando-o obrigatório sob pena de excomunhão: aquele que morria sem testar não podia, em princípio, ser enterrado na Igreja nem no cemitério (ARIĖS, 2014, p. 250).

Gradativamente 0 testamento tornou-se um ato formal de "direito privado [...] como era na Antiguidade romana" (ARIĖS, 2014, p. 250), destinado a fazer partilhas e transmitir as heranças dos bens terrenos. Contudo, o ato de testar, mesmo adentrando ao século XIX, em muitos casos não deixa de envolver tanto aspectos religiosos quanto civis, sendo composto geralmente por duas partes: "as cláusulas pias em primeiro lugar e, em seguida, a distribuição da herança" (ARIÈS, 2014, p. 251).

Para a produção do documento, recorria-se ao pároco ou ao notário por várias razões. A preocupação era formalizar, o máximo possível, a situação, buscando al guém que tivesse habilidade no trato de demonstrar verdadeiramente as últimas vontades, que tivesse autoridade para guardar os originais ou cópias, e que também fizesse cumprir os interesses do testador. Além, é claro, do analfabetismo disseminado, que induzia à necessidade de alguém que escrevesse pelos testados e, às vezes, até assinasse por ele a rogo.

Todos os documentos têm suas limitações e seus perigos para o historiador. Muitos questionamentos já foram feitos no que tange a utilização dos testamentos para o resgate do passado em suas diversas nuances, bem como o possível esgotamento do uso desta fonte pelo historiador 
(RODRICUES, 2015b, p. 17-49). Documentos bastante explorados, mesmo na academia brasileira, com o intuito de desvendar as "atitudes perante a morte" (GUEDES, 1986), que vão desde as vaidades (DAVES, 1998), os ritos fúnebres (REIS, 1991a, 1991b), os medos, os arrependimentos e os ajustes de contas com o divino (RODRIGUES \& DILLMANN, 2013). De forma semeIhante, os questionamentos podem ser direcionados ao inventário post-mortem (VALENTIM, MOTTA \& COSTA, 2013, p. 139-162; COSTA, 2013; LOPES, 2015; ARAÚjO, 2001, p. 54-58), que:

é o registro oficial do patrimônio deixado por pessoa falecida, do qual consta o tipo e o valor monetário dos bens acumulados ao longo da vida, bem como a lista de créditos (dívidas ativas) e débitos (dívidas passivas) pendentes. É o registro feito por autoridade pública e o documento tem valor para definir, em caráter final, o que caberá por partilha aos herdeiros, após honrados os débitos com o Estado e com credores particulares (MACALHÃES \& SILVA, 2002, p. 67).

No momento de arrolar e partilhar os bens do falecido, ou seja, de realizar o inventário, geralmente levava-se em conta os interesses dispostos nos testamentos. Entre eles, a separação dos valores para custear os encargos relativos aos funerais e ritos correlatos, que correspondia a uma fração apreciável do valor dos bens a serem transmitidos em herança.

Contudo, em cada período histórico e em cada espaço geográfico, dependendo das atividades desenvolvidas pelos indivíduos, os documentos produzidos têm suas especificidades (mesmo levando em conta as normas jurídicas e as mentalidades que pairavam sobre amplas realidades como a Colônia e depois Império brasileiro). Exemplo disso é que, mesmo que os testamentos e os inventários tenham sido redigidos baseados no Direito Canônico e/ou nas Ordenações Filipinas (e demais normas, inclusive as tradições), e reproduzidos constantemente em suas formas, as singularidades são visíveis em seus conteúdos, dependendo especialmente da dinâmica econômica das localidades ou regiões (ÂNGELO, 2013; RODRICUES, 2015a):

\section{Comportamentos diante da morte}

Para a realização deste estudo, foi delimitado o nordeste paulista nas décadas finais do século XVIII e a primeira metade do século XIX. A região encontra-se no interior da Colônia e depois Império brasileiro, confluência de caminhos oriundos de São Paulo de Piratininga em direção às minas do Centro-Oeste (Estrada dos Coyases), e da Picada de Goiás oriunda do Sul de Minas 
Cerais (Comarca do Rio das Mortes). Área inicialmente adentrada de forma rarefeita por paulistas, a região teve, no período em questão, ampla ocupação de migrantes mineiros, que se dedicavam à economia de abastecimento interno, capitaneada pela pecuária. Assim, o espaço delimitado nesta pesquisa passou por, transformações demográficas, sendo ocupado por populações oriundas de várias regiões, transformando a economia basicamente de subsistência em atividades dinâmicas produtoras de alimentos destinádos aos mercados internos de curta e longa distância (CHIACHIRI, 1986; OLIVEIRA, 1997; CUNHA, 2009; OLIVEIRA, 2013). Espaço específico que merece e justifica uma análise de fatias do comportamento humano, especialmente no período de tempo em que - segundo a historiografia - as preocupações com os registros que ditavam os trâmites, ritos e custos da morte eram (supostamente) cada vez menos especificados, denotando o processo contínuo de laicização da sociedade. Diante do exposto, os objetivos deste artigo são: conhecer a origem e o perfil dos testadores e inventariados, as transformações e continuidades das formas de declarar a relevância da fé católica, algumas razões que levaram a elaborar os testamentos, possíveis benesses concedidas aos herdeiros, os ritos prometidos e a parte material devida ao sagrado.

Serviram de suporte a esta pesquisa testamentos e inventários post-mortem selecionados no $\mathrm{Ar}$ quivo Histórico Municipal de Franca, interior de São Paulo. Ao vasculhar o acervo, percebe-se grande recorrência dos termos empregados nos testamentos e inventários do período, tanto sobre as causas pias, quanto sobre o patrimônio legado às instituições religiosas ou aos descendentes e aparentados. Desta forma, caso a opção metodológica fosse por um estudo seriado dos dados, resultaria em conclusões muito saturadas ${ }^{1}$. Assim, após a análise do acervo foram selecionados documentos representativos que dessem o devido suporte para o alcance dos objetivos propostos².

Entre os vários testadores, encontram-se os procedentes da Vila de São Paulo e os oriundos das Minas Gerais ou ainda seus descendentes, que permaneceram em torno da Freguesia e, depois, Vila Franca do Imperador, e de outras localidades na fronteira mineira. Também indivíduos ou sucessores que carregaram certos cabedais dos locais de origem, e mantiveram ou reproduziram seus recursos no contexto da economia de abastecimento na região, casando-se ou induzindo seus filhos a casarem-se entre famílias conhecidas, de mesma origem e detentora de certas posses (CUNHA, 2014, 2015a, 2015b, 2016).

1 Há um amplo debate exposto na obra de Cuedes et al (2015) sobre as metodologias a serem aplicadas em trabalhos que utilizam documentos eclesiásticos e civis que são tema deste artigo, e sobre a questão da padronização dos termos utilizados e, inclusive, sobre os modelos utilizados por clérigos e tabeliães.

2 Em torno de $1 / 4$ dos testamentos estão ilegíveis ou carecem de um tratamento especial para a leitura completa. Os inventários estão em bom estado de conservação e têm a leitura mais facilitada. É necessário ressaltar que somente possuidores de bens de maior valor, especialmente imóveis e escravos, realizavam os inventários formalmente, sabendo-se que estes eram somente uma fração da sociedade. 
O primeiro testamento analisado é o de João José de Souza, então casado com Luciana Angélica do Nascimento, que era uma das filhas do Capitão Hipólito Antônio Pinheiro ${ }^{3}$. João era

natural do Arrayal de Nossa Senhora da Piedade, Freguesia de Congonhas do Campo, bispado de Mariana, filho legítimo do Capitão Alexandre José de Souza e de Anna Angélica de Jesus, [este] falecido no mesmo Arrayal, morador do Termo da Villa Franca do Imperador (Arquivo Histórico Municipal de Franca. Testamentos, 1835).

O segundo documento aqui comentado é a testamentária de Ritta Angélica de Jesus, que foi cunhada de João José de Souza e irmã de Luciana Angélica do Nascimento, acima citados. Ritta era natural da Freguesia de Nossa Senhora do Desterro do Desemboque, e foi casada com seu primo de primeiro grau, Anselmo Ferreira de Barcellos (ANTÔNIO, 1999; SILVA, 1999). Nos anos iniciais do seu casamento, habitou com o marido, ambos na condição de agregados, o domicílio de Hypólito Antônio Pinheiro (pai de Ritta e tio/sogro de Anselmo). No ano de 1829, o mesmo casal encontrava-se em domicílio próprio, no Termo de Franca. Nesta ocasião, Ritta Angélica tinha 37 anos e seu marido, Anselmo, estava com 57 anos e era negociante. Conforme a Lista Nominativa de 1829, no domicílio deles foi arrolada, ainda, uma criança como agregada, e mais 11 escravos (Arquivo do Estado de São Paulo - Listas Nominativas de Habitantes, Franca, 1829. $2^{\mathrm{a}}$ Cia. de Ordenanças, fogo n.139). Ritta decidiu realizar seu testamento em 1855 , quando tinha 63 anos de idade (AHMF-TEST, 1855b).

O terceiro testamento, de 1855 , foi o de Joaquim Antônio da Silva, casado com Margarida Antônia, com quem não teve filhos. Joaquim era "natural e baptizado na Freguesia da Vila de Baependy, do Bispado de Mariana, filho de Cristina Antunez do Prado, já falecida, estando presente [no momento do testamento] na Fazenda de Monde Video, Distrito de Santa Ritta do Paraiso" (AHMF-TEST-1855a).

E, por fim, o quarto testamento é de Manoel Jozé A. Pereira, "casado à face da Igreja com Francisca Joaquim de Sales, ela filha de Pedro Martins Pacheco e Ana Felícia de Jesus, moradores na Província de Minas Cerais, de cujo matrimônio tive uma única filha, por nome Umbelina Roza de Nazareth" (AHMF-TEST-1858).

3 O referido Capitão Hipólito Antônio Pinheiro é originário de São José do Rio das Mortes, sul da Cápitania de Minas Cerais, cuja parentela espalhou-se pelo sertão do Rio Pardo. Cabe citar que a mãe de Hipólito deixou testamento datado de 1798, elaborado no Arraial do Rio do Peixe, freguesia de Congonhas do Campo, Termo de Queluz, Comarca de São João. Ana Rosa de Jesus, mãe de Hipólito, pediu em testamento "uma missa de corpo presente pela esmola de uma oitava de ouro e queimar uma vela de [...] libra e cada um (sacerdote) dirá missas nos oito dias (da morte) com esmola de $1 / 2$ oitava de ouro". Isso era mais ou menos $30 \$ 000$ réis, que correspondia à terça do inventário dela (AHMF-TEST-1798; INV-1798).

4 A partir deste ponto, serão utilizadas as siglas AHMF para Arquivo Histórico Municipal de Franca, TEST para Testamentos e INV pará Inventário post-mortem. 
Apesar de algumas passagens dos testamentos parecerem de praxe, todos os testadores fizeram a questão de declarar a fé católica, ou seja "no fim da vida, o fiel confessa sua fé, reconhece os pecados e os resgata por um ato público, escrito 'ad pias causas"' (ARIÈS, 2014, p. 250), conforme comprovam os exemplos a seguir:

Declaro que professo a Religião Cathólica, Apostólica Romana, em cuja fé pretendo viver e morrer (AHMF-TEST-1855b).

Como Christão Católico A. R. q. Sou, em a qual religião nasci e fui criado e educado, e em que me tenho conservado, e espero morrer (AHMF-TEST-1855a).

As razões para a tomada de decisão para registrar as últimas vontades formalmente eram, geralmente, em decorrência de estar adoentado ou em idade avançada, porém, com a ressalva de que estavam gozando de perfeito juízo e que era de vontade própria, como podemos observar:

[...] estando gravemente enferma, porém em meu perfeito juízo e entendimento, desejando dipor dos meus poucos bens, que Deos me confiou, como é minha vontade, faço este meo testamento (AHMF-TEST-1855b).

[...] estando em meo perfeito juízo, e entendimento por estar em avançada idade [...] considerando a morte, e que por isso devo dispor dos meos bens em ordem a salvar a minha alma faço 0 meu testamento (AHMF-TEST-1855a).

[...] tendo mesmo deliberado a fazer meu testamento, faço de minha livre vontade, e em meu perfeito juízo, declaro minhas dispuzições (AHMF-TEST-1858).

As nomeações dos testamenteiros levavam em conta o cônjuge, parentes próximos, pessoas com determinado vínculo, como o sogro, por exemplo, ou pessoas de estrita confiança.

Nomeyo em primeiro logar por minha testamentária e herdeira [...] minha mulher Luciana Angélica do Sacramento, em segundo o meu sogro, o Capitão Hipólito Antônio Pinheiro, em terceiro lugar, Manoel Ferreira de Menezes, queirão por serviço de Deos, por me fazer o favor ser meus testamenteiros e cumprir o que deixo determinado com livre geral administração dos meus bens (AHMF-TEST-1835).

Nomeio meos testamenteiros em primeiro lugar o Sr. Manoel Honório de Campos, em segundo o Sr. Joaquim Rodrigues Nunes, aos quais concedo os poderes em direito necessários e o tempo de quatro annos para prestação de contas no Juízo competente (AHMF-TEST-1855b).

Nomeio meos testamenteiros, em primeiro lugar o Sr. José do Carmo Gabriel, em segundo o Sr. José Manoel de Carvalho, em terceiro o meu liberto Estanislau Antônio, aos quaes e a cada um 
concedo todos os poderes em direito necessário, e ao que aceitar a administração desta minha testamentária [...] e o tempo de dois annos para a prestação das contas ao Juízo competente (AHMF-TEST-1855a).

Em alguns casos, são especificados bens a serem deixados para determinados herdeiros, estes citados por nome, parentesco, vínculo afetivo ou condição.social, como no caso de ex-escravos beneficiados por Joaquim Antônio da Silva. Porém, não havia por parte de todos a preocupação de relatar todos os bens, talvez devido à ciência de que o procedimento seria feito posteriormente por ocasião da abertura e tramitação do inventário post-mortem. Nem mesmo os escravos deixados aos sucessores são em todos os casos nomeados. Ritta Angélica de Jesus, mesmo tendo sido casada, não teve filhos e declarou não ter herdeiros necessários, descendentes ou ascendentes, instituindo como herdeiros os cinco filhos legítimos do seu primeiro testamenteiro, Antônio Honório de Campos, nomeados como Anselmo, Maria José, Antônio e Ritta em partes iguais. Porém, ressaltou que estes receberiam suas devidas partes somente depois de satisfeitas todas suas vontades especificadas no testamento (AHMF-TEST-1855a).

A mesma Ritta, então, especificou que deixava, separadamente, "ao menino Anselmo, filho legítimo de Manoel Honório de Campos e sua mulher Maria Ferreira, seis escravos; que são os seguintes: João da Crioula, José, Benedito e Verônica, Thiago Pardo e Clara (filha) de Eva Crioula". Eque deixava, também, para a afilhada Ritta (homônima da madrinha), filha do citado Manoel Honório, "um crioulinho de nome Anselmo, filho de Eva Crioula". Para além disso, deixou para o referido primeiro testamenteiro, pais dos seus herdeiros, "as casas que possuia no Arraial de Santa Rita", sem citar a quantidade, localização exata ou valor (AHMF-TEST-1855a).

Por sua vez, Joaquim Antônio da Silva, viúvo, sem "herdeiros necessários descendentes ou ascendentes", instituiu como recebedores das "benfeitorias, trastes de casa, ferramentas e de tudo o mais que se achar", os escravos a serem "libertos e igualmente aos que forão libertados pela finada [...] mulher". Porém, não esclareceu quantos cativos libertados receberiam os bens. A concessão aconteceria desde que fossem "satisfeitas as dívidas e disposições funerárias" (AHMF-TEST-1855a).

O testador Manoel José A. Pereira não esclareceu seus bens, porém, nomeou sua única filha, Umbelina Roza de Nazareth, como universal herdeira, a quem deixou por escrito um rol de todos os bens que poderia tomar posse por ocasião de sua morte. Por garantia, deixou "em mãos do testamenteiro outra lista igual" (AHMF-TEST-1858).

Como'era comum entre os testadores, chegava a hora de alforriar alguns de seus escravos, de 
forma condicional ou incondicional, com as alegações necessárias (Cf. TEIXEIRA, 2014). Foi o que fez Ritta Angélica de Jesus quando declarou:

deixo forras as minhas escravas Eva e Manoela pela boa conducta e fidelidade que digo com que, me tem servido; e cedo a cada uma dellas a sua roda de fiar. Declaro, igualmente forro e livre, o fiIho ou filha que a escrava Eva der à luz antes ou depois do meu falecimento (AHMF-TEST-1855b).

De forma um tanto diferenciada, Manoel Jozé A. Pereira concedeu os seus escravos à sua única filha Umbelina. Não obstante, recomendou que os cativos deveriam ser libertados somente após o falecimento da herdeira, como exposto:

que três escravos que tenho, a saber, Pedro, Francisca e Tereza, ficão sujeitos a Ihe servirem somente em sua vida, e que os trate com caridade, e recomendo muito à minha filha que antes de sua morte tenha o cuidado de lhes ter passado suas Cartas de Alforria liberta, para que depois de sua morte lhes serem entregues, e disto já eles estão cientes (AHMF-TEST-1858).

Quanto aos custos da morte, declarados monetariamente ou não, as encomendações procuravam especificar as providências em relação à mortalha a ser utilizada por ocasião do velório e enterro, ao acompanhamento do corpo e às missas de corpo presente. Se membro de uma irmandade, o testador comumente pedia que seu corpo fosse envolvido no hábito solene (vestimenta) de sua irmandade. É o caso de João José de Souza, quando declarou que, sendo "irmão do Santíssimo Sacramento", que o corpo fosse "envolto na mortalha [...] da dita irmandade, e sepultado na Matriz da Freguesia onde falecesse" (AHMF-TEST-1835). Ritta Angélica de Jesus, pediu com firmeza que o seu cadáver fosse vestido pelo "hábito de Nossa Senhora do Carmo" (AHMF-TEST-1855a). De forma semelhante, Manoel Jozé A. Pereira implorou ao testamenteiro que "logo que faleça e tenha de dar-se o corpo à sepultura [...] que seja envolto em um hábito da Ordem de São Francisco" (AHMF-TEST-1858),

O acompanhamento do féretro deveria ser feito pelos padres responsáveis pelas paróquias que também deveriam rezar as missas de corpo presente ou demais liturgias, como anotado:

(que meu corpo seja) acompanhado pelo Reverendo Pároco da dita Freguesia, com mais rigor que possível for, e offício de corpo presente com a missa (AHMF-TEST-1835).

Acompanhado solenemente á sepultura pelo meo Rdo. Párocho e mais sacerdotes que no lugar se acharem, os quaes dirão Mișsa de corpo presente por minha alma (AHMF-TEST-1855).

Declaro que na Freguesia donde eu morrer meu testamenteiro mandará dizer pela minha alma cinco missas de corpo presente (Idem). 
As solenidades deveriam ser normalmente cumpridas, porém, os testadores presavam pela simplicidade e distanciamento de qualquer arrogância por acasião da morte.

O cadáver exposto aos olhos de todos, depositado sobre terra ou no esquife de alguma irman-, dade, era apenas envolto numa mortalha, que poderia ser um simples lençol branco, símbolo do total despojamento das riquezas terrenas, ou o hábițo de uma ordem religiosa cuja regra se baseasse na humildade e pobreza. A utilização do caixã̃o era rara (DURÃES, 2000, p. 299).

Ao procurar seguir os conselhos de simplicidade no momento do passamento, assim ditou Ritta Angélica de Jesus: "meu cadáver (será) acompanhado à sepultura solenemente, porém, sem pompa ou vaidade mundana" (AHMF-TEST-1855b). De forma bem detalhada, inclusive excluindo a missa de sétimo dia, pediu Manoel Jozé A. Pereira:

que o esquife em for encerrado seja na maior simplicidade, sem galão algum nem de prata, e menos de ouro, e quando muito seja de lã preta, forro se necessário apenas de baeta, sendo conduzido o meu corpo em um carro coberto com esteiras sem signal ou designação alguma aparente, sendo conduzido depois ao último jazigo [...]. Declaro mais que hé minha vontade equero, que para minha morte não hajão mais signais ou toque de sinos, senão os recomendados pelo rito da Igreja em tais circunstâncias, e somente as encomendações que a Igreja ordena, com toda simplicidade que só exige ato religioso [...] também hé minha vontade que no dia subsequente ao meu enterro que se diga uma missa para minha alma, pois sempre julguei que o grande misterioso sacrifício que encerra o acto da celebração da missa não era necessário multiplicar-se para resgatar nossas almas. I gualmente é minha vontade que se evite a cerimônia da missa do sétimo dia, porque a considero como, ou uma oucazião pungente de dôres inúteis, ou como uma forma de affectação que dá lugar a comentários impróprios de uma oucaziã́o tão lúgubre e melancólica. Desejo que meu testamenteiro faça todos os esforços para que este acto do meu desaparecimento seja tão inapercebido como foi a minha vida; a que muito lhe recomendo, para que o verdadeiro dó só está nos corações sensíveis, e não nas exterioridades de representação estéril (AHMF-TEST-1858).

Para além das missas de corpo presente e de sétimo dia, há casos em que eram encomendadas muitas outras missas, inclusive para outras pessoas aparentadas, às vezes, especificando os custos. João José de Souza declarou que o "testamenteiro mandará dizer quarenta e duas missas pela minha alma, e fora a do meu funeral, na forma que ordeno". E mais, "mandará dizer dez missas pelas almas dos meus pays, e, e as esmolas delas serão as costumeiras pela freguesia" (AHMF-TEST-1835).

Os membros das irmandades geralmente deveriam pagar os chamados anuais, um determinado valor que era uma forma de manter o vínculo, participar dos ritos e ter benefícios como 
as orações pela alma após a morte (FREITAS, 1991). As preocupações com as pendências ou possíveis dívidas em relação às irmandades eram frequentemente citadas. João José de Souza ressal tou que era membro da Irmandade do Santíssimo Sacramento e também irmão da Santa Casa de Nossa Senhora das Dores: "cujas irmandades o testamento satisfará os annuais que por meu falecimento ficar devendo" (AHMF-TEST-1835).

\section{Preços da morte}

No entanto, além de certas concessões prometidas por ocasião do testamento, somam-se os custos que eram declarados em valores monetários. Ritta Angélica de Jesus especificou pagamentos no total de $70 \$ 000$ réis, assim distribuídos:

Deixo quarenta mil réis $(40 \$ 000)$ para se distribuírem em esmolas no dia do meu funeral para os pobres, com preferência os mais necessitados, cuja distribuição será feita a arbítrio e por conseIho do Reverendo Párocho do lugar. Deixo de esmola para as obras da Capela da Santa Ritta do Paraíso, trinta mil réis (30\$000). Deixo de esmola ao menino Fortunato, filho do finado Manoel Fortunato, que o criei em minha casa por caridade, cinquenta mil réis $(50 \$ 000)$. (AHMF-TEST$-7855 b)$.

João José de Souza também se procupava, naquele momento, com as obras das paróquias da Freguesia e com os pobres, cujo despreendimento totalizava $80 \$ 000$ réis, da seguinte maneira:

Declaro que de minha [...] se dará para as Obras de Nossa Senhora da Conceição desta Freguesia, cincoenta mil reys $(50 \$ 000)$. Declaro que deixo vinte mil reys $(20 \$ 000)$ para que meu testamenteiro reparta pelos pobres, doentes do mal de Lázaro desta Freguesia. Declaro que deixo dez mil reys $(10 \$ 000)$ de esmolla para as obras de Nossa Senhora do Rosário. (AHMF-TEST-1835).

Por sua vez, Manoel Jozé A. Pereira, pediu para ser conduzido ao "último jazigo da sepultura pelos pobres que aparecerem, a quem meu testamenteiro dará a cada hum a esmola de $\$ 320$ réis" (AHMF-TEST-1858).

Com outra preocupação que não as obras pias, Joaquim Antônio da Silva, mesmo nomeando seus três testamenteiros visando garantir as formalidades, avisou por escrito que deixaria "o prêmio de trinta mil réis" ( $30 \$ 000)$ para aquele, entre os indicados, que aceitasse a administração do testamento (AHMF-TEST-1855a). 
A outra base documental pesquisada, que também indica os custos da morte, é a dos inventários post-mortem. Como exemplo, separou-se aqui o inventário aberto em 1786, por ocasião da morte de José Barbosa de Magalhães, marido de Maria Pires de Araújo (ou Cordeira). O processo foi aberto no denominado Sítio das Lages, no Caminhos dos Coyases, então pertencente à Vila de São José de Mogi Mirim, cuja jurisdição correspondia, inclusive, ao Sertão do Rio Pardo. A descrição dos bens e seus valores foram separados em rubricas, especificando os valores (Quadro 1):

Quadro 1-Inventário de José Barbosa de Magalhães (1786).

\begin{tabular}{|c|c|c|}
\hline Relação de Bens & Valores & $\%$ \\
\hline Lançamento da prata, cobres e ferramentas & $9 \$ 560$ & 1,05 \\
\hline Cela, freio, lombilho e cangalha & $6 \$ 420$ & 0,70 \\
\hline Trastes de casa & $18 \$ 120$ & 1,98 \\
\hline Espingardas & $20 \$ 000$ & 2,19 \\
\hline Cavalos & $18 \$ 000$ & 1,98 \\
\hline Gado vacum e cabras & $63 \$ 760$ & 6,99 \\
\hline Oratório & $\$ 960$ & 0,10 \\
\hline Escravos & $528 \$ 000$ & 57,86 \\
\hline Bens de Raiz & $100 \$ 000$ & 10,97 \\
\hline Dívidas Ativas (a receber) & $147 \$ 880$ & 16,20 \\
\hline Monte Mor & $912 \$ 450$ & 100,00 \\
\hline Dívidas Passivas (a pagar)(") & $-32 \$ 720$ & $(3,58)$ \\
\hline Monte Menor & $879 \$ 730$ & $(96,41)$ \\
\hline Custas & $-28 \$ 000$ & $(3,06)$ \\
\hline Total líquido & $851 \$ 730$ & $(93,34)$ \\
\hline Meação (total líquido : 2) & $425 \$ 825$ & \\
\hline Terça (valor da Meação : 3) & $141 \$ 955$ & \\
\hline 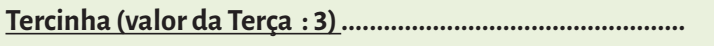 & $47 \$ 318$ & $\leftarrow$ \\
\hline Partível aos 7 filhos órfãos & $378 \$ 547$ & \\
\hline Valor a cada filho herdeiro & $54 \$ 078$ & \\
\hline
\end{tabular}

(*) $20 \$ 875$ réis referente ao funeral / Valores em mil réis.

Fonte: Elaborado pelo autor a partir do inventário de José Barbosa de Magalhães, de 1786 (AHMF).

O valor total dos bens de José Barbosa de Magalhães, somadas as Dívidas Ativas (a receber), totalizava $912 \$ 450$ réis. Subtraídas as Dívidas Passivas (a pagar), chegava-se ao Monte Menor 
de $879 \$ 730$ réis. Deste, deveriam ser subtraídos os custos do processo, que neste caso foi de $28 \$ 000$ réis, chegando-se ao Total Líquido de $851 \$ 703$ réis. O valor correspondente ao Total Líquido foi dividido na razão de $50 \%$ para a viúva e os outros $50 \%$ para os sete filhos. Da parte dos filhos é que foi calculada a Terça (uma terça parte dos $50 \%$ dos filhos, neste caso), correspondendo ao valor de $141 \$ 955$ réis, e daí calculou-se a Tercinha (que corresponde a um terço da Terça): $47 \$ 318=5,55 \%$ do total líquido, ou $11,11 \%$ da meação dos filhos. Cabe ressaltar que o cálculo da Terça somente foi feito para a obtenção da Tercinha, ou seja, este valor não foi subtraído do valor dos herdeiros ou percebido por terceiros. Dos $425 \$ 825$ réis foi retirado a Tercinha de $47 \$ 318$ réis (para atender as causas pias), resultando em $378 \$ 547$ reís, o que significou, para cada herdeiro, a soma de $54 \$ 078$ réis. Por fim, consta que: "Acharam mais, que da meação do Inventariado se tirou a Terça e desta a Tercinha para sufrágios de alma do Inventariado, a quantia de quarenta e sete mil trezentos e dezoito réis (47\$318)" (AHMF-INV-1786).

Contudo, o valor dos custos com o inventariado referente às questões religiosas não se resumiu à Tercinha. Entre as Dívidas Passivas (a pagar), foi declarado o valor de $20 \$ 875$ réis (63,74\% das dívidas), referente ao funeral, a saber: "devendo ao Reverendo Padre Francisco Bueno de Azevedo, de funeral e sepultura, conhecença [prestação ou tributo que se pagava aos padres] e outras miudezas sem crédito a quantia de vinte mil oitocentos e setenta e cinco réis (20\$875)" (AHMF-INV-1786).

Então, somados os valores das dívidas com o funeral de $20 \$ 875$ réis e a Tercinha "destinada aos sufrágios da alma" de $47 \$ 318$ réis, totalizava $68 \$ 193$ réis ou $8,08 \%$ do patrimônio líquido do inventariado José Barbosa de Magalhães.

À parte das dívidas vinculadas às questões religiosas, cabe ressaltar que o falecido ficou devendo ao Padre Francisco Bueno de Azevedo o valor de $3 \$ 365$ réis referente ao "abono" em uma negociação. Também devia "ao Padre Frei de Pádua, religioso de São Francisco", a quantia de $4 \$ 000$ réis, porém, neste caso não houve a especificação da causa. A soma dos valores correspondia a $22,50 \%$ das dívidas anunciadas. Noutros termos, especificamente estas dívidas inscritas aos sacerdores não têm qualquer vínculo com os funerais ou demais orações: eram notadamente dívidas de negócios mundanos.

Em 1788, antes do encerramento do inventário foi concedida vistas ao pároco que, por sua vez, emitiu a seguinte certidão: “Certifico que disse pela alma de José Barbosa de Magalhães duzentos e nove Missas que Ihe pertencia de sua Tercinha da Esmola, [...] cujas missas me encomendou a Inventariante Dona Maria Pires Cordeira, mulher que foi do falecido" (AHMF-INV-1786). Neste caso, o tabelião cercou-se de garantias para comprovar o pagamento das dívidas e, ao mesmo tempo, o pároco comprovou a quitação da parte que cabia à Igreja. 
De acordo com a certidão emitida, o referido padre afirma ter rezado 228 missas na intenção do falecido, isso correspondendo à Tercinha da Esmola estabelecida no inventário ( $47 \$ 318$ réis). Caso a correlação seja correta, talvez poderia ser possível realizar o cálculo chegando ao valor de $\$ 226$ réis cada missa. Um alto preço se comparados aos valores pagos por missas aos abastados em Portugal na mesma época, que era por volta de " 80 rs. cada uma" (DURÃES, 2000 , p. 335). Preço alto mesmo se a comparação for feita com valores dos bens anotados no inventário, conforme o Quadro 2.

Quadro 2-Inventário(Exemplos de bens: Cangalha/Trastes de casa/Gado bovino).

\begin{tabular}{|l|c|}
\hline Uma cangalha velha e desarreada & $\$ 320$ \\
\hline Um catre tecido de cipó em bom uso & $\$ 480$ \\
\hline Um par de botas & $\$ 800$ \\
\hline Um par de esporas & $\$ 640$ \\
\hline Três vacas com cria & $6 \$ 000$ \\
\hline
\end{tabular}

Fonte: Elaborado pelo autor a partir do inventário de José Barbosa de Magalhães, de 1786 (AHMF).

O inventário facilita a análise na medida em que são declarados valores dos bens e das concessões. Por exemplo, o valor de $68 \$ 193$ réis, separado do patrimônio líquido de José Barbosa de Magalhães para o velório e sufrágio da alma, era superior ao valor do gado escriturado no inventário, que era de $63 \$ 193$ réis, sendo a pecuária uma das principais fontes de sobrevivência no sertão. O mesmo valor ( $68 \$ 193$ réis) também superava o preço de uma escrava de oito anos de idade, avaliada em $60 \$ 000$ réis: Era também maior que todos os chamados trastes de casa e bens usados no trabalho cotidiano (cela, freio, lombilhos e cangalha), que valiam apenas $18 \$ 120$ réis (AHMF-INV-1786).

Há outros exemplos de inventariados que separaram valores bem maiores para as causas pias, porém, eram pessoas estabelecidas no entorno da Vila Franca do Imperador nas décadas iniciais do século XIX, quando a pecuária exercida na região tornara-se próspera e vinculada a outras áreas de São Paulo, Minas Gerais e Coiás. Isso resultou em inventariados de maior porte, que sendo oriundos de Minas, tinham provavelmente chegado ao nordeste paulista com certo cabedal, muitas vezes agraciados com heranças dos seus antepassados. Um exemplo é o inventário de Josefa.Comes Moreira, em que constam as suas dívidas com as instituições religiosas, entre elas a "quantia de $57 \$ 670$ devida ao vigário referente ao funeral, $25 \$ 000$ por direito ao Coral da Arqui Confraria da Vila Franca, e 48\$000, em dinheiro para o Coral da Ordem Terceira de São Francisco de Ouro Preto". Os valores são bem superiores àqueles referentes ao outro inventário acima descrito. Porém, a finada Josefa possuía um patrimônio total avaliado 
em $5: 654 \$ 403$ réis, e assim suas dívidas na rubrica causas pias totalizavam $130 \$ 670$ réis, o que correspondia a 4,62 da meação $0^{5}$. Inclusive, parte desta dívida deveria retornar às suas origens mineiras, Ouro Preto (AHMF-INV-1830).

Outro caso exemplar é o processo da inventariada Rosa Maria de Viterbo, cujos bens foram avaliados em 8:461\$650 réis (Monte Mor), incluindo terras (bens de raiz), escravos, gado e bens pessoais. Possuía dívidas (passivas) a pagar no valor de $449 \$ 000$ réis, resultando o Monte Menor em 8:012\$650 réis, que deveria ser dividido entre o inventariante, seu marido Antônio Vieira Velho $(50,0 \%)$, e os outros $50,0 \%$ aos seus nove filhos. Apesar da abastança, se comparados aos outros inventários da região nesta época, consta que deixou $10 \$ 000$ réis, ou $0,25 \%$ do valor da meação $0^{6}$, para os destinos da alma, assim anotado: "Haverão maz os mesmos Juiz Partidores que da meação da falecida inventariada clamo de facto se tirava para o Abenturado pela alma da mesma, a quantia de dez mil reiz (10\$000)." (AHMF-INV-1822).

\section{Considerações finais}

No contexto analisado, foi possivel observar a confiança nos párocos para elaboração dos testamentos em detrimento aos escrivães. Os sacerdotes seguiam uma espécie de modelo sequencial ao elaborar os testamentos para exprimir as vontades dos testadores baseadas na fé católica. A prioridade era para os rituais desejados por ocasião da morte. Os testadores solicitavam que as regras fossem as de praxe e sóbrias. As solenidades deviam expor os vínculos que teve em vida com as irmandades, corais, Santas Casas e demais instituições religiosas, como suas atitudes de boa vontade. Havia a preocupação com a simplicidade dos ritos, mas a morte deveria ser notada entre os vivos com um exemplo de descanso e redenção. Os testadores em idade avançada ou adoentados declaravam a vontade de realizar o acerto de contas com as pessoas próximas, e pedir a caridade e a misericórdia divina, fazendo bom uso dos bens terrenos, aquinhoando os parentes e apadrinhados, e até escravos, sem nunca esquecer das esmolas do enterro e da salvação da alma. Escolhiam a dedo os testamenteiros de confiança, que deveriam fazer cumprir os mandamentos.

De forma semelhante; os inventários post-mortem indicam, em um sentido mais quantitativo do que qualitativo, como os testamentos, as inquietações dos inventariados que, possuidores de poucos ou muitos bens, indicavam a transmissão de valores às instituições religiosas com a

5 Sem levar em consideração as custas do processo. 6 Idem. 
pretenção de resguadar a alma. Foi possível ainda notar que estes valores monetários proporcionais à riqueza foram declinantes no decorrer do tempo.

Os documentos aqui selecionados indicam a continuidade da ocupação de mineiros e seus descendentes na região, que foram sujeitos da dinamização da economia do nordeste paulista, sem perder vínculos com suas áreas de origem, inclusive manifestando interesse em retornar alguns recursos para instituições religiosas de Minas Gerais, por ocasião da morte.

No momento em que a idade ou as enfermidades representavam o peso da vida, a morte estabelecia o seu preço e a necessidade dos acertos de contas. Dependendo dos acertos, quando bem formalizados via testamentos e inventários, poderiam ser mais do que um ajuste com a vida, sendo até uma maneira de controle dos mortos sobre os vivos ao expressar suas vontades.

\section{Referências}

\section{Fontes primárias consultadas:}

AESP - Arquivo do Estado de São Paulo - LNH, Listas Nominativas de Habitantes, Franca, 1829. $2^{\mathrm{a}}$ Cia. de Ordenanças, fogo n.139.

AHMF - Arquivo Histórico Municipal de Franca "Capitão Hipólito Antônio Pinheiro"

INV - Inventário de José Barbosa de Magalhães - 1786.

INV-Inventário de Ana Rosa de Jesus - 1798.

INV - Inventário de Rosa Maria de Viterbo-1822.

INV-Inventário de Josepha Comes Moreira-1830.

TEST - Testamento de Ana Rosa de Jesus - 1798.

TEST - Testamento de João José de Souza, 1835.

TEST - Testamento de Joaquim Antônio da Silva, 1855a.

TEST - Testamento de Ritta Angélica de Jesus, 1855b.

TEST - Testamento de Manoel José A. Pereira, 1858. 


\section{Outras fontes bibliográficas:}

ÂNGELO, Fabrício Vinhas Manini. "Por muito amorque Ihe tenho": a família, as vivências afetivas e as mestiçagens na Comarca do Rio das Velhas (1716-1780). Dissertação (Mestrado em História)-Universidade, Federal de Minas Cerais, Belo Horizonte. 2013.

ANTÔNIO, E. M. M. Anselmada: a trama de uma sedição, 1838: Dissertação (Mestrado em História) Universidade Estadual Paulista, Franca, 1999.

ARAÚjO, Maria Lucília Viveiros. Contribuição metodológica para a pesquisa historiográfica com os testamentos. Histórica - Revista do Arquivo Público do Estado de São Paulo, São Paulo, v. 1, n. 6, out. 2015.

ARIÈS, Philippe. O homem diante da morte. Trad. Luiza Ribeiro. São Paulo: Unesp, 2014.

CHIACHIRI FILHO, José. Do sertão do rio Pardo à Vila Franca do Imperador. Ribeirão Preto: Ribeira, 1986.

COSTA, Fernando A. Alves da. E quanto valia afinal? O problema dos preços nos inventários post mortem do século XIX. História-Revista On-Line do Arquivo Histórico do Estado de São Paulo, v. 9, n. 60, dez. 2013.

CUNHA, Maísa Faleiros da. Demografia e família escrava, Franca-século XIX. Tese (Doutorado em Demografia)-Universidade Estadual de Campinas, Campinas. 2009.

Estudo das migrações internas no Norte Paulista, século XIX. In: ENCONTRO NACIONAL DE ESTUDOS POPULACIONAIS, 19., 2014. Anais... São Paulo: ABEP, 2014.

A dinâmica demográfica em Franca-SP, século XIX. Idéias,Campinas, v. 6, n. 1, p. 115-139, jan./jun. 2015a. Disponível em: <https://periodicos.sbu.unicamp.br/ojs/index.php/ideias/article/ view/8649480/16035>. Acesso em: mar. 2017.

Um Olhar sobre os Registros de Casamento da Paróquia Nossa Senhora da Conceição de Franca-SP, Século XIX. Dialogus, Ribeirão Preto, v. 11, n. 1 e 2, p. 37-47, 2015 b.

Nupcialidade da população livre e escrava em uma área de abastecimento interno. Franca-SP, século XIX. In: ENCONTRO NACIONAL DE ESTUDOS POPULACIONAIS, 20., 2016; CONGRESO DE LA ASOCIACIÓN LATINOAMERICANA DE POBLACIÓN, 7. 2016. Anais... São Paulo: ABEP; ALAP, 2016.

DAVES, Alexandre P. Vaidade das vaidades: os homens, a morte e a religião nos testamentos da Comarca do Rio das Mortes (1716-1755). Dissertação (Mestrado em História) - Universidade Federal de Minas Gerais, Belo Horizonte. 1998.

DURÃES, Margarida. "Porque a morte é certa e a hora incerta..." Alguns aspectos dos preparativos da morte e da salvação eterna entre os camponeses bracarenses (sécs. XVIII-XIX). Cadernos do Noroeste, Braga [Portugal], v. 13, n. 2, p. 295-342, 2000. [Sociedade e Cultura 2, Série Sociologia].

FREITAS, Nainôra Maria Barbosa de. O rosário de Maria e as suas irmandades. Segunda Metade do século XVIII. Dissertação (Mestrado em História) - Universidade Estadual Paulista, Franca. 1991. 
CUEDES, Sandra Paschoal Leite de Camargo. Atitudes perante a morte em São Paulo (séculos XVII a XIX). Dissertação (Mestrado em História) - Universidade de São Paulo, São Paulo. 1986.

LOPES, Luciana Suarez. Relato de pesquisa: a utilização dos inventários post-mortem como fonte de dados. Informações Fipe, São Paulo, p. 53-55, jul. 2015. Disponível em: <http://www.fipe.org.br/Content/ downloads/publicacoes/bif/2015/bif418-53-55-pesq.pdf>. Acesso em: mar. 2017.

MAGALHÃES, Beatriz Ricardina; SILVA, Vera Alice Cardoso. Evolução da economia e da riqueza na Comarca do Rio das Velhas - Capitania de Minas Cerais, 1713-1763. In: SEMINÁRIO SOBRE ECONOMIA MINEIRA, 10, 2002. Diamantina: Cedeplar, 2002.

OLIVEIRA, Lélio Luiz de. Economia e história. Franca, século XIX. Franca: Unesp/FHDSS; Amazonas Prod. Calçados S/A, 1997 (História Local, 7).

OLIVEIRA, Marina Costa de. Dinâmica populacional do Sertão do rio Pardo (1801-1829). Dissertação (Mestrado em História) - Universidade Estadual Paulista, Franca. 2013.

REIS, João José. Fontes para a história da morte na Bahia do século XIX. Caderno CRH, Salvador, v. 4 , n.15, p.111-122, jul./dez. 1991a. Disponível em: <https://portalseer.ufba.br/index.php/crh/article/ view/18829>. Acesso em: mar. 2017.

REIS, João José. A morte é uma festa. Ritos fúnebres e revolta popular no Brasil do século XIX. São Paulo: Companhia das Letras, $1991 \mathrm{~b}$.

RODRICUES, Cláudia; DILLMANN, Mauro. Desejando pôr a minha alma no caminho da salvação: modelos católicos de testamentos no século XVIII. História Unisinos, São Leopoldo, v. 17, n. 1, p.1-11, jan./abr. 2013. Disponível em: <http://revistas.unisinos.br/index.php/historia/article/view/htu.2013.171.01>. Acesso em: mar. 2017.

RODRICUES, Cláudia. Estratégias para eternidade num contexto de mudanças terrenas: os testadores do Rio de Janeiro e os pedidos de sufrágios no século XVIII. Locus - Revista de História, Juiz de Fora, v. 21, n. 2, p. 251-285, jul./dez. 2015a. Disponível em: <https://locus.ufjf.emnuvens.com.br/locus/article/ view/2883>. Acesso em: mar. 2017.

RODRICUES, Cláudia. O uso de testamentos nas pesquisas sobre atitudes diante da morte em sociedades católicas de Antigo Regime. In: GUEDES, Roberto; RODRICUES, Cláudia;

WANDERLEY, Marcelo da Rocha (Orgs.). Últimas vontades. Testamento, sociedade e cultura na América Ibérica, séculos XVII e XVIII. Rio de Janeiro: Mauad X, 2015b. p.17-49.

SILVA, F. L. C. P. A anselmada em Franca, século XIX: entre o conciliador e o quixotesco. Franca: Unesp-FHDSS, 1999.

TEIXEIRA, Heloísa Maria. Entre a escravidão e a liberdade: as alforrias em Mariana-MG no século XIX (1840-1888). Afro-Ásia, Salvador, in. 50, p. 45-92, dez. 2014. Disponível em: <http://www.scielo.br/scielo.php?script=sci arttext\&pid=S0002-05912014000200045\&lng=en\&nrm=iso >. Acesso em: mar. 2017. 
VALENTIN, Agnaldo; MOTTA, José Flávio; COSTA, Iraci del Nero da. Distribuição e concentração da riqueza com base em inventários post mortem na presença de casos de riqueza líquida negativa. História, Franca, v. 32, n. 2, p. 139-162, dez. 2013. Disponível em: <http://www.scielo.br/scielo.php?script=sci arttext\&pid=S0101-90742013000200008\&Ing=en\&nrm=iso > . Acesso em: mar. 2017. 